\title{
Elazığ İli İçme Beldesi Ekoturizm Potansiyelinin Değerlendirilmesi
}

\author{
Ebru Doğan ${ }^{1 *}$, Fatma Berfin Yamak ${ }^{2}$ \\ 1* Malatya Turgut Özal Üniversitesi, Sanat, Tasarım ve Mimarlık Fakültesi, Mimarlık Bölümü, Malatya, Türkiye, (ORCID: 0000-0002-3143-347X), \\ ebdu.dogan@ozal.edu.tr \\ 2 Malatya Turgut Özal Üniversitesi,Sanat, Tasarım ve Mimarlık Fakültesi,Mimarlık Bölümü, Malatya, Türkiye (ORCID: 0000-0003-0303-4057), \\ fatmaberfin.yamak@ozal.edu.tr
}

(International Conference on Design, Research and Development (RDCONF) 2021 - 15-18 December 2021)

(DOI: 10.31590/ejosat.1039389)

\begin{abstract}
ATIF/REFERENCE: Doğan, E., Yamak, F. B. (2021). Elazığ İli İçme Beldesi Ekoturizm Potansiyelinin Değerlendirilmesi. Avrupa Bilim ve Teknoloji Dergisi, (32), 86-91.

$\ddot{O} z$

Yaşam biçimi ve psikolojik gereksinimler sonucu insanların tatil ve dinlenme ihtiyacını karşılamak üzere çeşitli turizm faaliyetleri geliştirilmiştir. Ekoturizm, günümüz toplum ve devlet düzeninin getirdiği ekonomik kaygıya bağlı olarak sürdürülebilir ilkeler ve amaçlar çerçevesinde şekillenen turizm faaliyetlerinden biridir. Turizm potansiyeli olan doğal güzelliklerin, tarihi eserlerin ve bölge ekonomisine katkı sunacak çeşitli etkinliklerin değerlendirilmesi ile ekoturizm gerçekleşir.
\end{abstract}

Çalışmada, tarihi birikime ve doğal güzelliklere sahip İçme Beldesi’nin ekoturizm potansiyeli üzerine bir değerlendirme yapılmıştır. $\mathrm{Bu}$ bağlamda, ekoturizm ve bölge tarihi hakkında literatür çalışması yapılıış, bölgenin mevcut durumunu belirlemek üzere gözlemsel bir gezi düzenlenmiş̧tir. Elde edilen veriler ışığında, bölgenin ekoturizm açısından SWOT analizi yapılmış ve bölgenin ekoturizm merkezine dönüşümü için stratejiler sunulmuştur.

Anahtar Kelimeler: Ekoturizm, Sürdürülebilirlik, Turizm, İçme Beldesi.

\section{Evaluation of The Ecotourism Potential of İçme Town, Elazı ̆}

\begin{abstract}
As a result of lifestyle and psychological needs, various tourism activities have been developed to meet the holiday and rest. Ecotourism is a tourism activity that is shaped within the framework of sustainable principles and purposes, depending on the economic concern brought about by today's society and state order. Ecotourism is realized by evaluating natural beauties, historical artifacts and various activities that will contribute to the regional economy.

In the study, an evaluation was made on the ecotourism potential of İçme Town, which has historical background and natural beauties. In this context, literature study was conducted on ecotourism and the history of the region, and an observational trip was organized to determine the current situation of the region. Depending on the data obtained, SWOT analysis of the region in terms of ecotourism was made and strategies were presented for the transformation of the region into an ecotourism center.
\end{abstract}

Keywords: Ecotourism, Sustainability, Tourism, İçme Town.

\footnotetext{
*Sorumlu Yazar: ebru.dogan@ozal.edu.tr
} 


\section{Giriş}

Zaman içerisinde dünya üzerinde meydana gelen değişimler insan yaşamını olumsuz bir biçimde etkilemektedir. Bireylerin hayatları daha yoğun ve stresli bir hale bürünerek kalabalık yaşam döngüsü içerisinde kendilerine özel alan ve zaman yaratma konusunda yetersiz kalmaktadır. Özellikle son dönemde doğal afetlerin sayılarının ve şiddetlerinin artması, salgınlar, yaşanan ekonomik ve ekolojik krizler insan hayatını hem psikolojik hem de fizyolojik olarak olumsuz etkilemiştir. Değişen dünya koşulları ve yoğun yaşam temposu içinde insanlar buldukları her boşlukta kendilerine vakit ayırmak, gündelik yaşamlarından uzaklaşıp rahatlamak istemektedir. İnsanlar bu istekleri doğrultusunda çeşitli tatil etkinliklerine katılarak, fiziksel ve psikolojik açıdan kendilerini yenileyebilirler. Temel ihtiyaçlar ve fiziksel koşullar karşısında, tatil etkinliklerinin daha sağlıklı, doğal ve sürdürülebilir çevrelerde yapılmasına son dönemde talep artmıştır. Bu tür etkinlik potansiyeline sahip alanlar, kurum ve kuruluşların yapacağı çalışmalar, devlet teşvik ve destekleri, toplumsal etkinlikler ile birlikte insanların hizmetine sunularak bölgenin ekonomik yönden gelişmesine, yöre halkı üzerinde sürdürülebilir çevre ve yaşam bilincinin oluşmasına katkı sağlar.

İnsanların yaşadıkları yer dışına, maddi gelir elde etmeden, politik ya da askeri amaç olmadan, merak, din, sağlık, spor, dinlenme, iş, kültür, deneyim kazanma gibi amaçlarla, kişisel olarak ya da grup şeklinde gerçekleştirdikleri seyahatlerden, gittikleri yerde sürekli olmamak şartı ile konaklamalarına bağlı olarak ortaya turizm kavramı çıkmıştır. Turizm kapsamında gerçekleştirilecek etkinlikler, turizmin gerçekleştirilme amacına ve kişi sayısına bağlı olarak şekillenmektedir. Birey ya da bireylerin ihtiyaçlarına bağlı olarak turizm çeşidi değişiklik göstermektedir (Kabataş, 2020).

Turistin geldiği yere, katılan kişi sayısına, katılanların yaşlarına ve katılanların amaçlarına göre turizmi farklı sınıflara ayırmak mümkündür. T.C. Kültür ve Turizm bakanlığına göre turizmin çeşitleri: Sağlık ve termal turizm, yayla turizmi, kış turizmi, mağara turizmi, av turizmi, kongre turizmi, golf turizmi, yat turizmi, İpekyolu, inanç turizmi, hava sporları, dağcılık, akarsu-rafting turizmi, su altı dalış ve kuş gözlemciliği şeklindedir (Budak Çetin, 2021). Değişen yaşam şartları, toplum düzenleri, çalışma koşulları gibi parametreler doğrultusunda insanlar artık tatillerini güneş, deniz, kum üçlüsü yerine göl kenarı, ormanlık alan, şelale, dağlık alan gibi doğal alanlarda geçirmeyi tercih etmektedir (Sayın, 2019).

Turizmin kültürel ve doğal kaynaklar çerçevesinde gelişmesinin ne kadar önemli olduğunu idrak edebilen ülkeler, sahip oldukları kaynakları koruyarak gelecek kuşaklara aktarmak ve ekonomik kazanç sağlamaya devam edebilmek için sürdürülebilir turizm politikalarına önem vermektedir. Böylece doğal kaynakların bilinçli bir şekilde kullanılması ve turizm sektörünün yaratmış olduğu olumsuz etkilerin azaltılması sağlanmaktadır. Bu durumda turizmin ekonomik, sosyal ve çevresel getiri seviyesi de artmaktadır (Nalınçak, 2020).

İnsanların turizm anlayışının değişmesi ile birlikte ekoturizm gündeme gelmiş, kitle turizminin doğaya vereceği tahribatı azaltmak ve doğaya zarar vermeden sürdürülebilir bir turizm faaliyeti gerçekleştirmek olarak değerlendirilmiştir.
Ekoturizm kaynaklarının devamlılığının yanı sıra yöre halkı için sosyo ekonomik kalkınmayı sağlayacak bir firsat olarak değerlendirilmeye başlanmıştır (Sayın, 2019).

Bazı durumlarda sürdürülebilir turizm ile aynı anlamda kullanılan ekoturizm, sürdürülebilir turizmin bir alt dalını oluşturmaktadır. Ekoturizm ev sahipliği yapan bölgenin sahip olduğu özellikleri koruyarak ve en az zarar görecek şekilde ziyaret etkinlikleri gerçekleştirilmesini ifade etmektedir (Nalınçak, 2020).

Ekoturizmin amac1; kitle turizminin aksine belirli bir dönemde artış gösteren turist sayısını azaltıp yıl içerisine yaymak, doğal ve yapılı çevreye yönelik baskıyı ve zararı önlemeyi amaçlayarak uzun süreli ekonomik çıkarları gözetmektir (Budak Çetin, 2021). Ekoturizmin belirlediği bu özellikler doğa tabanlı olması, muhafaza ve korumayı içermesi, eğitim, kültür, fayda sağlama ve etik çerçevesinde birleşmektedir (Nalınçak, 2020).

Uluslararası Ekoturizm Topluluğu' na göre ekoturizm şu ilkeleri taşımalıdır (Sevinç, 2019):

- Çevre ve yerel halk üzerinde en az olumsuz etkiyi yapacak bir kullanım tarzını belirlemek.

- Alanın doğal ve kültürel sistemine karşı duyarlılığı ve bilinci arttırmak.

- Yasal olarak yönetilen ve diğer doğal alanların yönetimi ve korunmasına katkı sağlamak.

- $\quad$ Alanda yapılacak turizm miktarı ve türünün belirlendiği karar verme aşamasında ve uzun dönemde yerel halkın katılımını sağlamak.

- Yerel halka ekonomik ve diğer faydalar sağlamak, ekoturizmde yerel halktan çalışanlar kullanmak.

Ekoturizmin en önemli özelliği doğal çevreden zevk almak ve bunun yanında doğayı korumak için destek sağlamaktır. Doğal alanlarda koruma düşüncesi, eğitimin önemli hale gelmesi ve eğitim olanaklarının güçlenmesi ile gerçekleşir. Doğal alanların sürdürülebilirliği konusunda yapılan birçok tartışmada doğal kaynakların önemi ile ilgili politikalar izlenilmedikçe ekoturizm için uygun alanların her dönem tehlike içerisinde olabileceği görülmektedir (Sayın,2019).

Ekoturizm pek çok açıdan insan yaşamı, toplum düzeni ve ülke yönetimi için önemli katkılar sağlamaktadır. Bu nedenle ekoturizm potansiyeli yüksek olduğu düşünülen alanlarda yapılacak çalışmalar ile ekoturizminden maksimum düzeyde faydalanmak mümkündür. Ekoturizm faaliyetlerinin kente sunduğu olanakları gözönünde bulunduran Elazığ ili valiliği 2019 yılında, Elazığ'ın ilk 'Eko-Köy Projesi' için çalışmalara başlamıştır. Konu ile ilgili yapılan incelemeler doğrultusunda İçme Beldesi' ni çalışma alanı olarak belirlemiştir (Elazığ Valiliği, 2019). Hem tarihi hem de doğal birikim ve güzelliğe sahip İçme Beldesi'nde ekoturizm kapsamında gerçekçi, ekolojik ve ekonomik sürdürülebilirliğe katkı sağlayacak çalışmalara ihtiyaç duyulmuştur. Bu bağlamda çalışmada, sahip olduğu potansiyel ve yapılan yerel girişimler doğrultusunda İçme Beldesi inceleme alanı olarak olarak belirlenmiştir. 


\section{Materyal ve Metot}

Çalışmanın amacı, Elazı̆̆ İli, İçme Beldesi’ nin sahip olduğu doğal ve tarihi değerlerinin turizm potansiyelini değerlendirerek, ekoturizm çerçevesinde uygulanabilir çalışmaları ortaya koymaktır. Yerel yönetimlerin ve yöre halkının beldenin tarihi ve doğal değerlerini fark etmeleri, beldenin ekonomik, sosyal, kültürel gibi pek çok açıdan kalkınması için önerileri sunmayı hedeflenmektedir.

Tablo 1. SWOT matrisi (Bakoğlu,2010).

\begin{tabular}{|c|c|c|}
\hline FAKTÖRLER & $\begin{array}{l}\text { GÜÇLÜ YANLARI } \\
\text { G1: ......... } \\
\text { G2: ......... }\end{array}$ & $\begin{array}{l}\text { ZAYIF YANLARI } \\
\text { Z1: } \ldots \ldots \ldots \ldots \\
\mathrm{Z} 2: \ldots \ldots \ldots \ldots\end{array}$ \\
\hline $\begin{array}{l}\text { FIRSATLAR } \\
\text { F1: } \ldots \ldots \ldots \ldots \\
\text { F2: } \ldots \ldots \ldots \ldots .\end{array}$ & $\begin{array}{l}\text { GF STRATEJISİ } \\
\text { Firmaların güçlü yanları } \\
\text { ile firma dışı firsatlar ile } \\
\text { avantaj sağlanması için } \\
\text { oluşturulur. }\end{array}$ & $\begin{array}{l}\text { ZF STRATEJISİ } \\
\text { İşletmenin zayıf olduğu } \\
\text { kısımlarını azaltmak için } \\
\text { dış çevrenin sunduğu } \\
\text { firsatlardan } \\
\text { yararlanabilmesi için } \\
\text { oluşturulur. }\end{array}$ \\
\hline 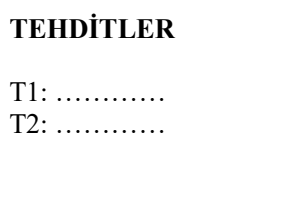 & $\begin{array}{l}\text { GT STRATEJISİ } \\
\text { Firma dışı oluşan } \\
\text { tehditleri, firma içi güçlü } \\
\text { yanları ile gidermek ya } \\
\text { da azaltmak için } \\
\text { oluşturulur. }\end{array}$ & $\begin{array}{l}\text { ZT STRATEJISİ } \\
\text { Firmanın sahip olduğu } \\
\text { zayıf tarafları dikkate } \\
\text { alarak, dış çevrenin } \\
\text { oluşturduğu tehditleri } \\
\text { azaltmak için oluşturulur }\end{array}$ \\
\hline
\end{tabular}

Çalıșmada öncelikle, turizm, ekoturizm, sürdürülebilir turizm kavramları ve çalışma alanının tarihi hakkında literatür araştırması yapılmıştır. Ekoturizm kavramının tanımı, amac1, genel özellikleri ile yerleşim yerinin tarihsel süreci ortaya konulmuştur. Çalışma alanı olarak belirlenen İçme Beldesi' ne gözlemsel bir gezi düzenlenmiş, bölgenin mevcut durumu yerinde incelenmiştir. Çalışma kapsamında yapılan gezi sonucunda elde edilen verilere bağlı olarak bölgenin ekoturizm açısından sahip olduğu güçlü ve zayıf yanları (iç faktörleri) belirlenmiştir. Ayrıca bölgenin ekoturizm gelişiminde politik, ekonomik, sosyo-kültürel ve teknolojik yönden var olan firsat ve tehditleri (dış faktörleri) tespit edilmiştir. Bu dört temel değişken SWOT matrisinde (Tablo 1) analiz edilmiş ve bölgede ekoturizmin gerçekleşmesi için uygulanabilir stratejiler belirlenmiştir. Böylece çalışma ile birlikte, İçme Beldesi' nin ekoturizme kazandırılması için yerel yönetim ve bölge halkının yararlanabileceği rehber niteliğinde bilgiler sunulmuştur.

\section{Bulgular ve Tartışma}

\section{1. Çalışma Alanı}

İçme beldesi; kalesi, mağarası, su pınarı, çeşmesi, eğitim yapıları, camileri ve diğer yapı türleri ile Elazığ ilinin en eski yerleşim yerlerinden biridir. Öyle ki; İçme bölgesinde bulunan ve yaklaşık M.Ö. 2000 yılına dayanan kalıntılar bulunmuştur. Birçok kültür ve medeniyetlere ev sahipliği yapan İçme, Elazı̆̆e-ISSN: 2148-2683
Palu yolunun 30. kilometresinde yer almaktadır. Elazı̆̆’a 35 km, Kovancılar ilçesine $33 \mathrm{~km}$ uzaklıkta bulunan İçme beldesinin batısında Elazı̆ ve Malatya, doğusunda Bingöl güneyinde Diyarbakır kuzeyinde ise Tunceli illeri bulunmaktadır. Keban barajı'nın oluşturduğu göl kıyısında ve Elazığg-Bingöl karayolu üzerinde yer alan İçme beldesi, Mastar dağ konumlanmıştır. Aşağı İçme, Yukarı İçme, Keban Deresi çevresi İçme beldesinin önemli yerleşim yerlerindendir. (Şekil 1)

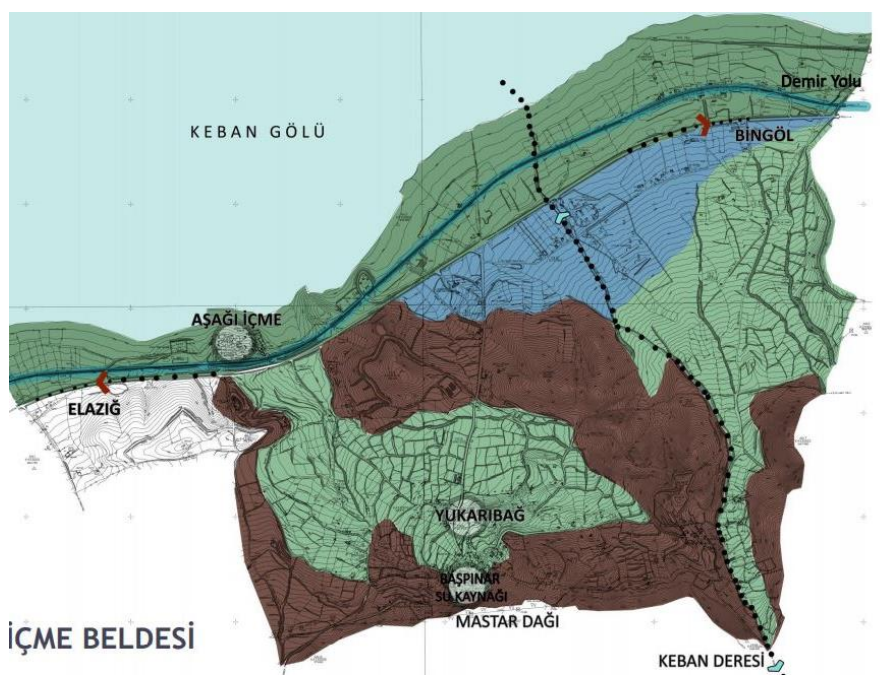

Şekil 1. İçme beldesi genel görünüm

1970'li yıllara kadar İçme halkı yoğun bir biçimde tarım ile ilgilenmiştir. Altınova adıyla bildiğimiz doğunun ve ülkemizin can damarı olan ovada tarım faaliyetini gerçekleştirmiştir. Cumhuriyet döneminde şeker fabrikasının kurulması ile önemli bir merkez haline gelen İçme beldesi kurulan fabrikanın kaldırılması ile zamanla önemini kaybetmiştir. Ayrıca İçme bölgesi 18. ve 19. Yüzyıllarda el sanatlarında önemli bir gelişim göstermiş ve bölgenin üretim kültürüne katkı sağlamıştır.

Geçmişte karasal iklimin hüküm sürdüğü İçme, yapılan ve yapılmakta olan barajların etkisi ile 1lıman bir iklime geçiş yapmıştır. Bu sürecin sonucunda özellikle önceleri çok soğuk ve yoğun kar yağışlı geçen kış ayları günümüzde nispeten daha ılıman geçmektedir. Keban barajının yapılmasından sonra tarıma elverişli toprakların büyük bir kısmı su altında kalmıştır. Baraj suyunun geniş alanlara nüfus etmesi önemli tarım arazilerinin azalmasına neden olurken balıkçılık faaliyetlerinin gerçekleşmesine katkı sunmuştur. Su kaynağı bol olan İçme'de, buğday, arpa, armut, kayısı, ceviz, badem ve dut yetişmektedir. Yetiştirilen ürünler arasında üzüm ve şeker pancarı, tarımsal faaliyete ek olarak da küçükbaş hayvancılık en önemli gelir kaynakları arasındadır.

Doğal güzellikleri, soğuk suları, havuz başları, bağ ve bahçeleriyle son zamanlarda halkımızın ilgi gösterdiği mesire yerlerinden biri haline gelmiştir. Keban barajının oluşturduğu göl kıyısında bulunan Aşağı İçme, baraj suyunun görsel etkisiyle bölge halkı tarafindan ilgi odağı haline gelmiştir.

\section{2. İçme Beldesinin Ekoturizm Olanakları}

İçme beldesi ekoturizm potansiyeli yüksek olan bir yerleşim alanıdır. Pek çok farklı açıdan ekoturizm faaliyetlerinin gerçekleşmesine imkân sağlayacak doğal güzelliklere ve tarihi 
oluşumlara ev sahipliği yapar. Belde içerisinde ekoturizme uygun alanların başında su kaynakları gelmektedir. Özellikle Başpınar su kaynağı ve Keban deresi bu açıdan önemli olmaktadir.

Geçmişte bir manastır olarak inşa edilen, bir dönem karakol ve belediye binası olarak kullanılan tarihi binanın avluya bakan kısmında bulunan Başpınar su kaynağı bugün atıl halde bulunmaktadır. Başpınar su kaynağının günümüze ulaşan özgün kısımları tespit edilip konservasyonunun sağlanarak iyileştirilmesi ve çevresinin rekreasyon alanları ile desteklenmesi ile birlikte beldenin gelişimine katkı sağlanabilir. Ayrıca Başpınar su kaynağının çevresinde 11 adet su değirmeni olduğu bilinmektedir. $\mathrm{Bu}$ değirmenlerin restorasyon çalışması geçirmesi ve işletilmesi ile birlikte turistler için çekim noktası oluşturulabilir.

İkinci bir su kaynağı olan Keban deresinin 1slahı başta olmak üzere çevredeki tarım arazilerine sulama suyu sağlamadaki inovatif çözümler belde için etkili olabilir. Keban deresi ve çevresinin özellikle de derenin Keban gölü ile birleştiğ kıyı bölgesinde rekreatif çalışmalar yapılabilir. Derenin su ve debi analizlerinin yapılması sonucunda belirlenen en uygun noktada yöresel mimari özelliğe sahip ve günümüz teknolojisi ile entegre edilmiş (geleneksel ve çağdaş yapım sistemlerinin buluştuğu) bir değirmen tasarımı yapılabilir. Dere ile ilişkilendirilecek yürüme yolları, kamp ve mesire alanları ile bölgede cazibe alanları oluşturulabilir. Ayrıca bölgedeki su kaynaklarının mevcut potansiyellerinin günümüz teknolojisi ile değerlendirilmesi sonucunda yenilenebilir enerji (su, rüzgar, güneş vb.) kullanımına yönelik çalışmalar yapmak mümkündür.

İçme beldesinin tarihi geçmişinin uzun y1llara dayandığ bilinmektedir. $\mathrm{Bu}$ tarihi birikim doğrultusunda da alan üzerinde günümüze kadar ulaşmış çok sayıda tarihi yapı bulunmaktadır. İçme geleneksel konutu üzerinde restorasyon çalışmaları yapılabilir. Restorasyonu önerilen yapılara butik otel, konut, kent belleği müzesi gibi yeni işlevler verilebilir. İçme beldesinde tarihi ve kültürel nitelik taşıyan sivil mimari örneklerinin sayısı yok denecek kadar az olduğundan, tarihi hafizayı gelecek nesillere aktarmak maksadı ile bir sokak üzerinde yeni yapılacak konutların içme bölgesinin geleneksel yapım sistemine uygun bir şekilde rekonstrüksiyonu sağlanarak tarihi bir sokak dokusu yaratılabilir.

2171 metre yükseklikteki Mastar dağı konumu itibari ile bir seyir tepesi niteliği taşımaktadır. Ayrıca doğal bitki örtüsünün çeşitliliği ve karlı gün sayısının fazlalığı nedeniyle dağ ve doğa yürüyüşleri için idealdir. Turistlerin ve bölge halkının trekking olarak kullanabilecekleri uygun rotalar Başpınar su kaynağının arkasından yükselen Mastar Dağı çevresine yerleştirilebilir ve gezi parkuru olarak yeniden düzenlenebilir. Mastar Dağı eteklerinde bisiklet sürme ve binicilik gibi bir çok rekreasyon faaliyeti ve etkinliği de oluşturulabilir. Düzenlenecek gezi rotalarının engelli vatandaşların da kolay erişebileceği ve kullanabileceği standartlar dâhilinde planlanması sağlanmalıdır.

İçme beldesinde, geleneksel tarım yöntemleri kullanılarak, çeşitli tarım ürünleri (buğday, arpa, üzüm...) üretilebilir. Tarımda kullanılacak yöresel tohumların yetiştirilmesi sonucunda geleneksel tarım ürünlerinin ve işlenmiş hallerinin satışı arttırılarak belde halkının ekonomik gücünün artması sağlanabilir. Ayrıca geçmişten günümüze ulaşmış beldenin geleneksel mutfak kültürünün yaşatılması ve tanıtılması ile ilgili çalışmalar yapılabilinir. Bölgede köy içinde ve Elazığ çevre yolu üzerinde belirli noktalarda, İçme yerleşim alanında üretilmiş ve işlenmiş tarım ürünleri ile geleneksel mutfağının tanıtımının yanında satışı da gerçekleştirilebilir. Üretilen ürünlerin ülke ve dünya pazarında yer bulması sağlanabilir. Bölgede yetişen ürünlerin tanıtımı ve bölge turizmini canlandırmak adına yılın belirli dönemlerinde Müzik, Hasat ve Gastronomi Festivalleri yapilabilir.

Keban barajının yapılması ve beldenin Keban gölüne kıyısının olması İçme kıyı bölgesinin oluşmasına neden olmuştur. Yeme içme birimlerinin yer aldı ̆̆ı, olta balıkçılığının desteklendiği ve manzara fotoğrafı çekimlerine olanak tanıyan rekreatif bir alan olarak kıyı bandı yeniden düzenlenebilir. Ayrıca İçme'nin kıyı bölgesi ile Mastar Dağı arasında yürüme ve bisiklet yolları düzenlenip bu alanlar farklı fonksiyonlardaki birimler ile desteklenebilir. Böylece bölgenin kıyı ve iç kesimleri arasında kesintisiz bir sosyal, kültürel ve etkileşim aksı sağlanmış olur.

\subsection{SWOT Analizi}

Bölgeye yapılan gözlemsel gezi ve çalışma kapsamında yapılan literatür araştırması sonucunda bölgenin güçlü ve zayıf yanları ile sahip olduğu firsat ve tehditleri belirlenerek SWOT analizi yapılmıştır. Elde edilen veriler Tablo 2 ve Tablo 3 'te sunulmuştur.

Tablo 2. İ̧me beldesinin ekoturizm potansiyelini etkileyen iç faktörler

\begin{tabular}{|l|}
\multicolumn{1}{|c|}{ İç Fakörler } \\
\hline Güçlü Yanlar \\
\hline G1: Doğa turizmine yönelik yapılacak etkinlikler için uygun \\
zemin ve alan yapısına sahip olması. \\
G2: Trekking, kampçılık, dağcılık ve diğer yürüyüşs sporları \\
için doğal parkur ve rotaların bulunması. \\
G3: Başta su kenarları olmak üzere birçok alanın rekreasyonel \\
etkinliklere uygun olması. \\
G4: Ekoçiftliklerin oluşturulması bakımından uygun tarım \\
alanların bulunması. \\
G5: Tarihi bakımından yapıları, mutfak kültürü ve el sanatları \\
ile zengin bir geçmişe ve birikime sahip olması. \\
G6: Belde halkının ekoturizm faaliyetlerinin yapılmasına 1lımlı \\
yaklaşması. \\
G7: Baraj suyunun su sporlarına ve balıkçılığa elverişli olması. \\
G8: Baraj sonrasında bölgenin sulama problemi ortadan \\
kalktığından tarımsal ürün çeşidi ve miktarının artması. \\
G9: Baraj sonrası karasal iklimin yerini ılıman bir iklimin \\
alması. \\
G10: Fauna ve flora bakımından çeşitliliğe sahip olması. \\
G11: Önemli yerleşim bölgelerine erişim sağlanan ana ulaşım \\
yoluna yakın olması. \\
G12: Fotoğraf çekimleri için eşsiz doğal ve tarihi güzelliklere \\
sahip olması. \\
G13: Mevcut su kaynaklarının yenilenebilir enerji \\
potansiyellerinin olması \\
Zayıf Yanlar \\
\hline Z1: Ekoturizm için etkin kullanılabilecek potansiyele sahip \\
olan alanların bir kısmının atıl durumda olması. \\
\hline
\end{tabular}


Z2: Tarihi alanların ve yapılan tahribatın fazla oluşu.

Z3: Beldeden kente göçün olması.

Z4: Keban deresinin işlevini yitirmiş olması.

Z5: Su değirmenlerinin zamanla işlevini yitirmesi ve terk edilmesi.

Z6: Baraj yapımı sonrası önemli tarım ve tarihi yerleşim alanlarının sular altında kalması.

Z7: Karavan ve diğer araçlar için otopark alanların yetersiz oluşu.

Z8: Geleneksel üretime katkı sunan el sanatları ile uğraşan kişilerin sayısının azalması.

Z9: Engelli vatandaşlar için alanın mevcut topografyasının ve tesislerinin uygun olmaması

Tablo 3. Içme beldesinin ekoturizm potansiyelini etkileyen dış faktörler

\section{Dış Fakörler}

\section{Firsatlar}

F1: Ekoturizm ile yeni istihdam alanlarının oluşma potansiyeli. F2: Diğer illerden ziyaretler için havaalanı ve çevredeki illere yakın konumda olması.

F3: Ekoturizm yatırımları için birçok ulusal ve uluslararası kurumların bu konudaki destek, teşvik ve hibe sağlama isteği. F4: Yerel yönetimlerin son dönemlerde bölgenin ekoturizm potansiyelini fark etmesi.

\section{Tehditler}

T1: Yerel ve ulusal idarelerin kırsal turizm için yeterli planlamalarda bulunmamalar1.

T2: Plansız ekoturizmin gelişimi ile tarımsal alanların azalması. T3: Beldenin, fay hatların olmasından dolayı, deprem riski taşıması.

T4: Tarım arazilerinin yerleşime açılması.

T5: İstihdam çalışmalarının eksikliği.

T6: Kentin önemli donatı alanları ve cazibe merkezlerinin kent merkezinde olmas1.

T7: Tarım ürünlerinin işlenmesi ve satışı için bölgeye destek ve teşviklerin yapılmaması.

T8: Belde ile ilgili bilimsel ve akademik çalışmaların sayısının yetersizliği.

T9: Mevcut su kaynaklarının yenilenebilir enerji potansiyellerinin olmasına rağmen yerel yönetimler tarafından yeterli çalışamalrın yapılmaması ve bu alanların atıl durumda olmasi

T10: Engelli vatandaşlara yönelik yerel yönetimlerin erişim ve ulaşım rotalarını oluşturmaması

\section{Sonuç}

Tarihi, kültürel birikimi ve doğal güzellikleri tespit edilen beldenin ekoturizm potansiyeline sahip olduğu belirlenmiştir. Ekoturizm uygulaması ve sürekliliği, İçme Beldesi’nin kalkınması, gelişmesi ve sosyo-ekonomik açıdan ilerlemesi için oldukça önemlidir. Gerekli fizibilite çalışmaları yapıldığında aktif bir şekilde ilin ve beldenin kalkınmasına katkı sağlayacağı düşünülmektedir. Bu bağlamda, İçme Beldesi'nde, ekoturizmin uygulanabilmesi için bölgenin mevcut durumu SWOT yöntemi ile analiz edilmiş ve elde edilen verilere bağlı olarak yerel e-ISSN: 2148-2683 yönetimin ve halkın uygulayabileceği stratejiler geliştirilmiştir (Tablo 4).

Tablo 4. İçme beldesinde ekoturizm uygulaması için SWOT matrisinden elde edilen stratejiler

\section{Stratejiler}

\section{GF Stratejiler}

GF1: Kültürel mirasın ve geleneksel mimari yapıların korunmasına yönelik yerel yönetimler, üniversiteler ve sivil toplum kuruluşlarının birlikte hareket etmesini sağlamak.

GF2: Ulusal ve yerel düzeyde stratejiler hazırlamak, planlama, yöntem ve izlemeye yönelik özel gelişim planları oluşturmak. GF3: Gelişim, uygulama ve eylem planlarını düzenlemek. GF4: İlçede tüm paydaşların destekleri ile düzenlenecek festival ve şenliklerin ( gastronomi, müzik, sanat vb tanıtımlarını yapmak.

GF5: Bölgeye yönelik ekoturizm haritasının çıkarmak ve tanitmak.

\section{ZF Stratejiler}

ZF1: Tarihi ve doğal mirası belgeleyerek koruma çalışmalarını gerçekleştirmek.

ZF2: Kültürel varlıkları, çeşitli tanıtımlar, festivaller ve konferanslarla ön plana çıkarmak.

ZF3: Sanal gerçeklik alt yapısı kullanılarak su altında kalan tarihi ve kültürel mirasın tanıtımını yapmak.

ZF4: Bölgede oluşturulacak tesislerde engelliler için tasarım kriterlerini zorunlu hale getirmek.

\section{GT Stratejiler}

GT1: Belde halkının da katılım sağlayacağı yeni istihdam alanlarını yaratmak ve yeni iş kollarında görev alacaklara uzman eğitimleri vermek.

GT2:Yönetimlerce fiziksel alt yapı ve rekreatif alanların yetersizliğini çözmeye yönelik çalışmalar yapmak.

GT3: Eğitsel, bilimsel, kültürel amaçlı çalışmalara destek verilerek, bunların sayılarını arttırmak.

GT4: Ulusal ve uluslararası fon desteklerinden yararlanarak bölgenin su kaynaklarının yenilenebilir enerji potansiyellerine yönelik çalışmalar yapmak

GT5: Sağlanacak ekonomik destek ve hibe ile tarım faaliyetlerinin türünü ve sayısını arttırmak.

\section{ZT Stratejiler}

ZT1: Koruma amaçlı imar planını oluşturmak.

ZT2: Doğal afetlere karşı risk analizlerini ve raporlarını hazırlamak.

ZT3: Bölgeye kolay ve rahat ulaşım yolları ile otopark alternatiflerini oluşturarak trafik güvenliğini sağlamak. ZT4: Bölgedeki gezi rotalarının ve rekreatif alanların düzenlenmesinde engelliler için tasarım kriterlerini de kullanmak.

Teknik ya da teknolojik bir altyapı gerektirmeyen SWOT analizi statik ve öznel olduğundan, çalışmada oluşturulan matris sonucunda en iyi stratejinin seçilmesi değil uygulanabilir 
stratejilerin belirlenmesi hedeflenmiştir. Çalışma kapsamında, İçme Beldesi'nde ekoturizmin gerçekleşmesi için SWOT matrisinden elde edilen uygulanabilir stratejiler Tablo 4'te sunulmuştur. Yapılan bu çalışma sonrasında, stratejilerin doğru bir planlama dâhilinde sırası ile uygulanmalıdır. Bu bağlamda, yönetimler (ilgili bakanlıklar, müdürlükler, valilik, belediyeler, kaymakamlıklar, muhtarlıklar... vb), üniversiteler, sivil toplum kuruluşları ve halkın, uygulanabilir stratejilerin öncelik ve önem derecelerine birlikte karar vermeleri önerilmektedir.

Ekolojik turizm uygulamasının bölgede gerçekleşmesi sonrasında ilin sahip olduğu tarihi, kültürel ve doğal nitelik taşıyan diğer yerleşim alanları ile eş zamanlı ve sistematik bir biçimde çalışması ve planlanması önem taşımaktadır. $\mathrm{Bu}$ bağlamda UNESCO sürecine hazırlanan Harput'un ve güneydoğu yamacında konumlanan Hüseynik gibi pek çok tarihi yerleşim alanlarıyla birlikte düşünülerek üst ölçekte Elazı̆̆ ili için sürdürülebilir turizm haritasının ivedilikle hazırlanması gereklidir.

\section{Kaynakça}

Bakoğlu, R. 2010. Çağdaş Stratejik Yönetim. İstanbul: Beta Yayınları, 1-336.

Budak Çetin, F. 2021. Doğal Peyzajların Turizm Açısından Ekonomiye Katkıları: Bursa Sadağı Kanyonu ve Çevresi Örneği. Yüksek Lisans Tezi. Bartın Üniversitesi Lisansüstü Eğitim Enstitüsü Peyzaj Mimarlığı Anabilim Dalı, Bartın, 1104

Elazı̆̆ Valiliği. 2019. Elazığ'ın İlk 'Eko Köy Projesi' Hayata Geçiyor. http://www.elazig.gov.tr/elazigin-ilk-eko-koyprojesi-hayata-geciyor (Erişim tarihi: 01.06.2021)

Kabataş, E. 2020. Kırsal Alanlarda Ekoturizm Potansiyelinin Belirlenmesi: Kırklareli İli Kofçaz İlçesi Örneği. Yüksek Lisans Tezi. Tekirdağ Namık Kemal Üniversitesi Fen Bilimleri Enstitüsü Peyzaj Mimarlığı Anabilim Dalı, Tekirdağ, 1-224

Nalınçak, S. 2020. Sürdürülebilir Ekoturizm: Her Zaman Mümkün Mü?. Yüksek Lisans Tezi. İzmir Katip Çelebi Üniversitesi Fen Bilimleri Enstitüsü Ekoturizm Anabilim Dalı, İzmir, 1-86

Sayın, G. 2019. Kayseri İli Doğal Peyzajlarında Ekoturizm ve Görsel Peyzaj Kalitesi Üzerine Bir Araştırma. Yüksek Lisans Tezi. T.C. Kahramanmaraş Sütçü İmam Üniversitesi Fen Bilimleri Enstitüsü Peyzaj Mimarlığı Anabilim Dalı, Kahramanmaraş, 1-123

Sevinç, M. S. 2019. Ekoturizm Potansiyeli İzmir Çiçekli Köy Örneği.Yüksek Lisans Tezi. İzmir Katip Çelebi Üniversitesi Fen Bilimleri Enstitüsü Ekoturizm Anabilim Dalı, İzmir, 175 